\title{
Pathomorphological changes in the organs of chickens infected spontaneously by the species Salmonella pullorum on private farms in Chernivtsi region
}

\author{
O. Shchebentovska*, A. Kostynuk*, S. Zaika**, L. Kovalova**, L. Yevtukh**, M. Holubtsova* \\ *Stepan Gzhytskyi National University of Veterinary Medicine and Biotechnologies, Lviv, Ukraine \\ **Polissya National University, Zhytomyr, Ukraine
}

Article info

Received 25.09.2021

Received in revised form 18.10.2021

Accepted 20.10.2021

Stepan Gzhytskyi

National University

of Veterinary Medicine

and Biotechnologies,

Pekarska st., 50,

Lviv, 79010, Ukraine.

Tel.: +38-032-275-65-13.

E-mail:pk_vetuniver_lv@

ukr.net

Polissya National

University; Staryi Blvd., 7

Zhytomyr, 10008, Ukraine.

Tel.: $+38-067-701-81-46$.

E-mail:

schebentovskaolga@

gmail.com

\begin{abstract}
Shchebentovska, O., Kostynuk, A., Zaika, S., Kovalova, L., Yevtukh, L., \& Holubtsova, M. (2021). Pathomorphological changes in the organs of chickens infected spontaneously by the species Salmonella pullorum on private farms in Chernivtsi region. Regulatory Mechanisms in Biosystems, 12(4), 614-619. doi:10.15421/022184
\end{abstract}

Commercial poultry production growth and the increase in the number of small farms specializing in raising broiler chickens, laying hens, quails, and other poultry contribute to the spread of infectious diseases. Non-compliance with the principles of biosafety during incubation and breeding results in mass deaths of poultry and, consequently, significant economic losses for farmers. Salmonellosis is one of the most dangerous anthropozoonotic diseases of poultry, which is most often registered in private farms. Age analysis of the poultry salmonellosis in the EU countries indicates the infection of adult laying hens most often, young poultry to a lesser extent, and chickens aged up to 10 days less frequently. Although the program for the prevention and elimination of poultry salmonellosis has been approved at the legislative level in Ukraine, monitoring studies are not carefully conducted. This is especially true for private homesteads and small farms, which greatly complicates the epizootiological situation in some regions of the country. The article describes the pathological and histological changes in the liver, heart, lungs, kidneys, and spleen. The changes were detected in chickens aged 10 and 14 days infected with microorganisms of the species Salmonella pullorum. Eggs for incubation were obtained from different family flocks, and incubation was performed in a single incubator. The initial clinical signs of the disease appeared in chickens aged 7 days and included diarrhea, increased water consumption, lameness, mass concentration of chickens near heat sources, nervous phenomena in the form of circle walking, and partial blindness in some cases. The pathological autopsy revealed hepatomegaly with sharp change in the organ colour, diapedetic hemorrhage under Glisson's capsule, and diffuse miliary necrosis. Greyish-white nodular lesions of the lungs and heart, dystrophic changes in the kidneys, and deposition of uric acid salts in the ureters were also characteristic features. Diffuse coagulation necrosis, massive perivascular infiltration by heterophilic lymphocytes and stasis were observed in the liver. Changes in the heart were characterized by significant infiltration by mononuclear cells and heterophiles, which led to atrophy, necrosis, and replacement of cardiomyocytes by connective tissue cellular elements. Delymphatization and necrosis of the lymph nodes were pronounced in the spleen.

Keywords: hepatomegaly; miliary necrosis; cardionecrosis; delymphatization; lymphoid nodules; heterophilic infiltration.

\section{Introduction}

Poultry breeding, especially as a commercial venture, grows rapidly every year in Ukraine. It is considered one of the key elements in elaborating economic and food security strategy. Supporting poultry production is important for domestic agricultural producers in terms of expanding exports of poultry meat, egg powder, and eggs to the EU countries. Ultimately, it also results in improving the welfare of the Ukrainian population. However, like every industry, poultry deals with its peculiar challenges. Seasonal viral diseases, especially Newcastle disease and avian influenza cause significant damage. Bacterial diseases, especially those caused by microorganisms of the genus Salmonella (family Enterobacteriaceae) also prevent poultry farming from bringing optimal results. Within the genus, salmonellae are differentiated by serotypes. This depends on their antigenic structure, i.e. the availability and combination of two main antigenic complexes: somatic $\mathrm{O}$-antigen and flagellar $\mathrm{H}$-antigen (absent in immobile strains). According to antigenic affinity, salmonellae are divided into 52 groups including more than 2,300 serotypes, of which more than 230 are isolated from birds and more than 700 from humans (Shivaprasad, 2000; Amy et al., 2004). Poultry salmonellosis causes significant economic losses due to the high mortality rate and temporary production downtime with the implementation of all quarantine measures (Calnek et al.,
1997; Khan et al., 1998; Wigley et al., 2002). The spread of salmonellosis both in private homesteads and industrial facilities has occurred due to the increase in the number of small poultry farms, incubation of eggs from different family flocks, and violation of basic biosafety principles on the part of the rural population working in commercial poultry farms. The age prevalence of poultry salmonellosis in the EU countries is most often registered in industrial flocks of adult laying hens and less often in young chickens up to 10 days of age (Rosu et al., 2007; Saha et al., 2012; Wang et al., 2020). In Ukraine, monitoring studies of salmonellosis in small farms and private homesteads are not conducted carefully, which complicates greatly the epizootological situation in some regions of the country.

Salmonella is a poly-pathogen, but the poultry diseases are caused by $S$. enteritidis, $S$. pullorum, $S$. gallinarum in most cases and $S$. thompson, S. heidelberd, S. anatum, S. haifa, S. infantis less often. Chickens are natural hosts for both S. pullorum and S. gallinarum and these can remain in the organism without causing any clinical manifestation of the disease (Snoeyenbos et al., 1991; Nazir et al., 2012). The overall resistance potential of the organism declines in case of virological pressure, violation of zootechnical parameters, improper feeding, and inappropriate use of antibacterial drugs. As a consequence, favourable conditions for the development of pathogenic microflora emerge, including Salmonella microorganisms. Typhus is a disease caused by a microorganism of the species 
S. gallinarum, which usually affects adult chickens and results in a high mortality rate (Christensen et al., 1992).

Pullorosis is usually detected in chickens up to two weeks of age (Prasanna \& Paliwal, 2003). The etiology of pullorosis was first described by Rettget in 1899. The scientist called the disease "fatal sepsis of young chickens". The term "pullorosis" was first introduced in 1929, until then the disease was defined as "bacillary white diarrhea". The bacterium S. pullorum is a causative agent of pullorosis. By its tinctorial properties, it is a stationary, gram-negative thin rod without a capsule with rounded edges which does not form spores, 1.0 to $2.5 \mu \mathrm{m}$ in length and $0.3-1.5 \mu \mathrm{m}$ in width. The main path of pullorosis transmission is the transovarial one, i.e. via the egg. Eggs can be infected with Salmonella in two main ways. Salmonella infects the ovaries of hens and penetrates the eggs before they form a shell. Also, salmonella-infected bird droppings can penetrate the smallest pores of the damaged eggshells, thus causing infection (Garcia et al., 2010; Paul et al., 2015; Kashani et al., 2021). Our work aims to describe pathomorphological and pathohistological changes in the organs of chickens during their transovarial lesions by microorganisms of the species Salmonella pullorum on private farms of Chernivtsi region.

\section{Materials and methods}

Clinical and experimental studies were performed in accordance with the requirements of the European Convention for the Protection of Vertebrate Animals used for Experimental and Other Scientific Purposes (Strasbourg, 1986).

The corpses of Dominant breed chickens aged 10 and 14 days, kept on four small private farms in Chernivtsi region were selected as the material for the study. For incubation purposes, 20 thousand eggs were obtained from laying hens in two different farmlands of Chernivtsi region. However, the incubation itself was carried out in a single private incubator. Aerosol vaccination of chickens from Gumboro disease, infectious bronchitis, and Newcastle disease was performed. After that, four farms were chosen and each one received five thousand chickens. The chickens showed no signs of the disease by the 7th day of their life. The first clinical manifestations appeared almost simultaneously on the 7th day on all farms. Diarrhea started, water consumption increased, some chickens showed nervous disorders, i.e., they threw their heads back and walked in circles. They significantly lagged in growth on the 14th day. The mortality rate in the first days after the appearance of clinical signs ranged from 5\% to $15 \%$ ( 250 to 750 chickens). In general, the mortality rate of chickens aged up to 20 days was about $50 \%$. Fragments of internal organs selected for histopathological examination were fixed in a $10 \%$ aqueous neutral formalin solution, washed in water, dehydrated in an ascending row of alcohols, and poured into paraffin according to the conventional method. Histocuts with a thickness of $7 \mu \mathrm{m}$ were made from paraffin blocks using a sled microtome MS-2. Deparaffinized sections were stained with Mayer's hematoxylin and eosin (Merkulov, 1969). Light microscopy and microphotography of the obtained histopreparations were performed using Leica DM-2500 microscope, Leica DFC 450C camera, and Leica Application Suite Version 4.4. The microbiological examination was performed by selecting material from the cadaveric liver, followed by seeding on selective RajHans medium and bismuth sulfite agar. After growth, pure cultures were isolated and biochemical identification was performed using a colour series. The isolated pathogen had typical salmonella biochemical properties, i.e., it fermented levulose, mannose, xylose, arabinose, and glucose to form acid, cleaved maltose and mannitol to acid, did not ferment lactose, sucrose, dulcitol, and did not form indole.

\section{Results}

Clinical signs of the disease in chickens during their first week of life were somewhat different. They did not lose appetite for six days and were lively. However, massive signs of depression and refusal to feed appeared from the 7th day. Some chickens stood motionless with their heads down, others walked in circles with their necks turned or, lying on their backs, spun around. Some chickens walked around the poultry house with their eyes closed and hit their feeders and drinkers. Most chickens with clinical signs of the disease demonstrated weakness, thirst, and watery diarrhea.
Over the next few days, signs of airway damage were recorded. The chickens sat with their beaks open and breathed heavily. Mass death of poultry was registered even without visible clinical manifestations of the disease since the 10th day of life.

The pathological autopsy revealed a sharp increase in the liver and gallbladder overflow with thick, viscous, and dark green bile. There were diapedetic hemorrhages under Glisson's capsule (Fig. 1a) and miliary foci of necrosis in the parenchyma (Fig. 1b, c). Fatty degeneration was registered less often. Multiple necrotic foci of greyish-white colour were observed in the heart and lungs (Fig. 1d, 2a, b). Some chickens suffered from serous pericarditis. The kidneys were sharply enlarged, light brown with spotted hemorrhages (Fig. 2c), the vessels and the ureters were full of blood and uric acid salts respectively.

The spleen was slightly enlarged or unchanged with small parenchyma hemorrhage (Fig. 2d). The small intestine's mucous membrane was slightly thickened and light red with watery content. Diapedetic hemorrhages occurred in the rectum and the cloaca was full of light green manure. Microscopically, multifocal hepatocyte necrosis (Fig. 3 a), sharply dilated central veins, and intraparticle capillaries were detected in the liver of chickens aged 10 and 14 days. Plasmocytes and lymphocytes concentrated around necrotized hepatocytes (Fig. 3b). In addition, massive leukocyte infiltrates were found around the triads and perivascular zones (Fig. 3c). Colonies of microorganisms were observed in the mass of necrotized hepatocytes, as well as in vessels (Fig. 3d).

Massive diffuse coagulation necrosis of lymphoid nodules (Fig. 4a, b) and white pulp delimpatization were found in the chickens' spleen. This testified to the immunosuppressive state. The lung tissue vessels were full of blood, with their walls fibrous and swollen. Parabronchids were infiltrated by heterophilic lymphocytes and plasma cells (Fig. 4c). The alveoli epithelial tissue was preserved. There was significant cellular infiltration of lymphocytes, histiocytes, and macrophages in the peribronchial connective tissue (Fig. 4d).

Morphologically, massive areas with necrosis of cardiomyocytes and pronounced proliferation by heterophilic lymphocytes were found in the heart muscle (Fig. 5a, b). Stagnation and hemorrhage into the interstitial tissue were typical in the kidneys. The lymphocytes and heterophiles were located between the dystrophically altered tubules in most chickens (Fig. 5c). Diffuse hemorrhagic infiltration of the mucous layer, desquamation of the apical part of the villi, and cellular infiltration of the mucosal plate were observed in the rectum (Fig. 5d). Most crypts were necrotized, while others were dystrophically altered. The muscle layer was thickened.

Analyzing the variability of pathomorphological changes recorded in the chickens aged 10 and 14 days at various farms, the following relationship was found: $65 \%$ of the chickens suffered from hepatomegaly with diapedetic hemorrhage and multifocal necrosis in the organ's parenchyma and cardionecrosis with heterophilic infiltration; $25 \%$ had fatty degeneration of hepatocytes, $36 \%$ had acute venous hyperemia of the lungs with necrotic foci and perivascular heterophilic infiltration, $17 \%$ suffered from pneumonia, 13\% had catarrhal hemorrhagic enteritis and colitis (Table 1).

\section{Discussion}

Our research results correlate with the reports of other scientists (Basu et al., 1975; Arora et al., 2015), who recorded $89.5 \%$ of poultry deaths in the Indian states of Karnataka, Maharashtra, and Tamil Nadu caused by microorganisms of the species S. pullorum. Clinical manifestations of the disease, such as depression, anorexia, greenish-yellow diarrhea, and nervous phenomena in the form of the head tilt were detected in 2001 during the salmonellosis outbreak in the state of Tripura in eastern India. The pathological autopsy revealed fatty liver degeneration with miliary parenchyma necrosis. S. pullorum was isolated from the gallbladder. Similar changes in the liver were described by Basnet (Basnet et al., 2008; Belih et al., 2016) in adult laying hens infected with $S$. gallinarum.

Chishti (1985) also recorded a bronze colour of the liver with diapedetic hemorrhages and necrotic foci. Chisti et al. (1985) and Hafeeji et al. (2001) found necrotic foci in the heart, hemorrhages and miliary necrosis in the spleen, acute venous stasis, and nodular lung damage caused by S. pullorum. Stagnant phenomena with hemorrhages in a mucous membrane were expressed in the intestine. 

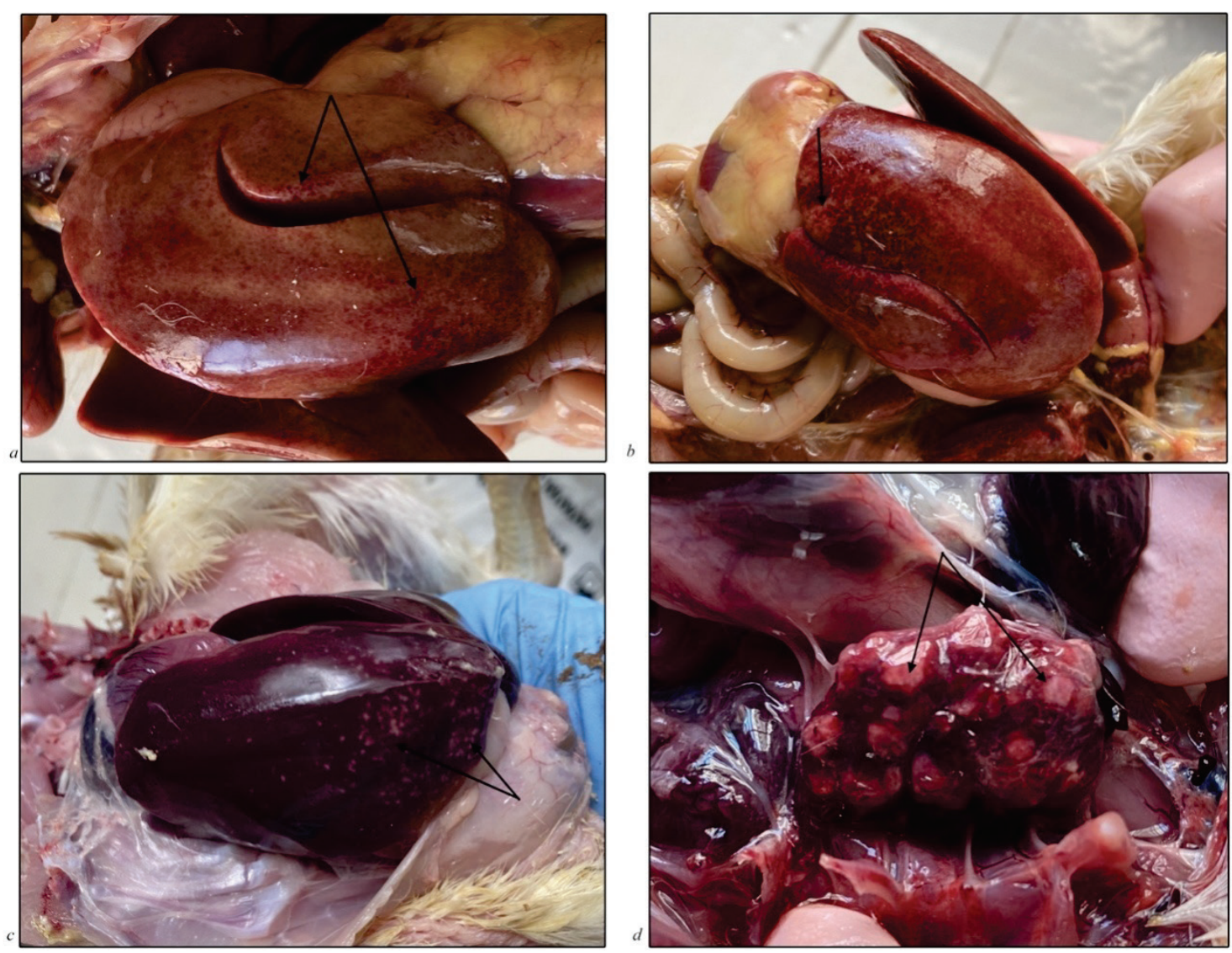

Fig. 1. Morphological changes in the organs of chickens infected with Salmonella pullorum:

$a$-liver dystrophy; diffuse diapedetic hemorrhages under the liver capsule in chickens aged 10 days; $b$ - hepatomegaly; necrosis outbreaks (arrow); $c$-liver; diffuse foci of necrosis in chickens aged 10 days (arrow); $d$ - diffuse necrotic foci in the lung parenchyma (arrows)
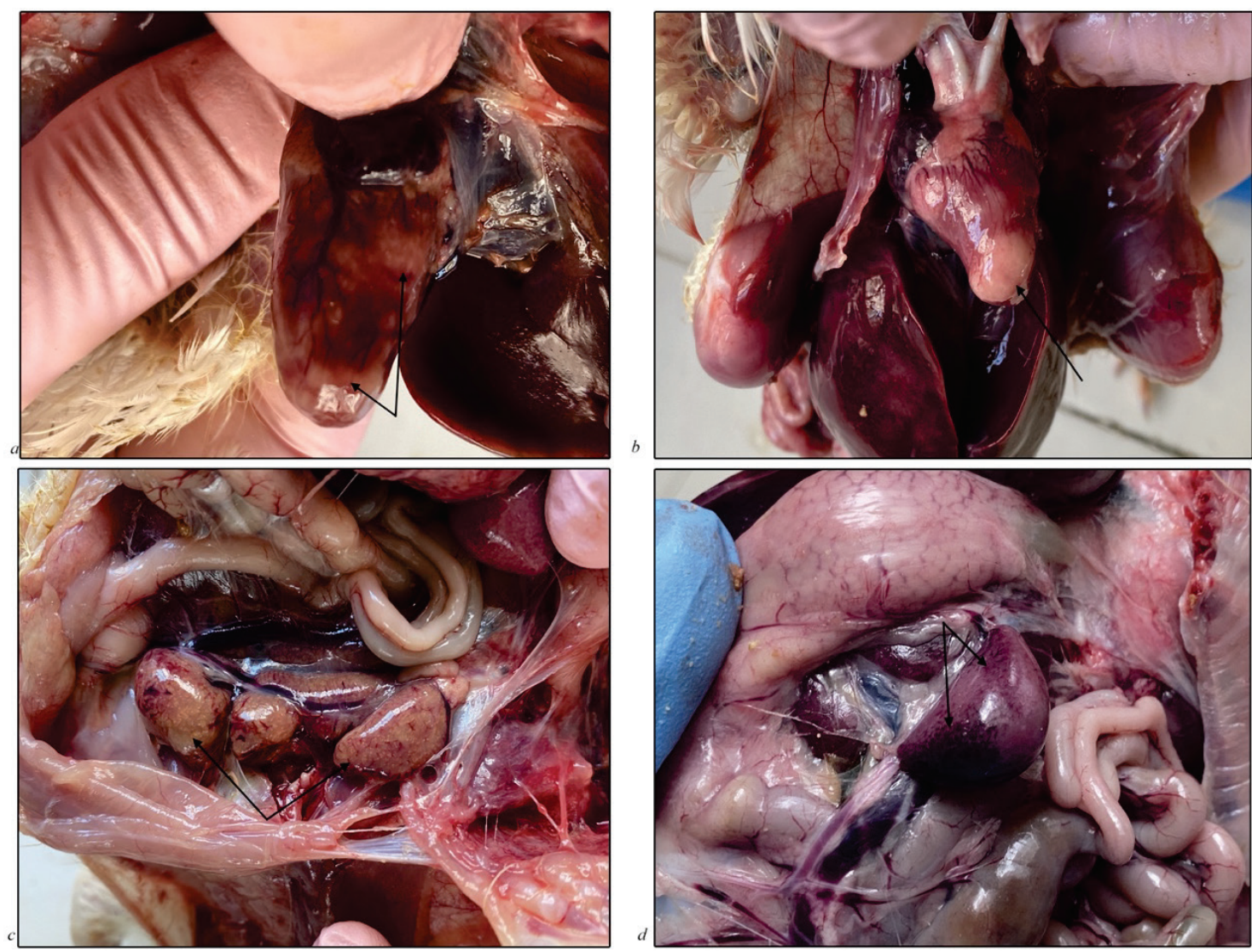

Fig. 2. Morphological changes in the organs of chickens infected with Salmonella pullorum:

$a$ - the heart: diffuse necrotic foci in the myocardium (arrows); $b$ - the heart: massive focus of necrosis (arrow); $c$ - sharply enlarged and dystrophically altered kidneys of chickens aged 10 days (arrows); $d$ - the spleen of chickens aged 10 days: hemorrhages under the capsule (arrow) 

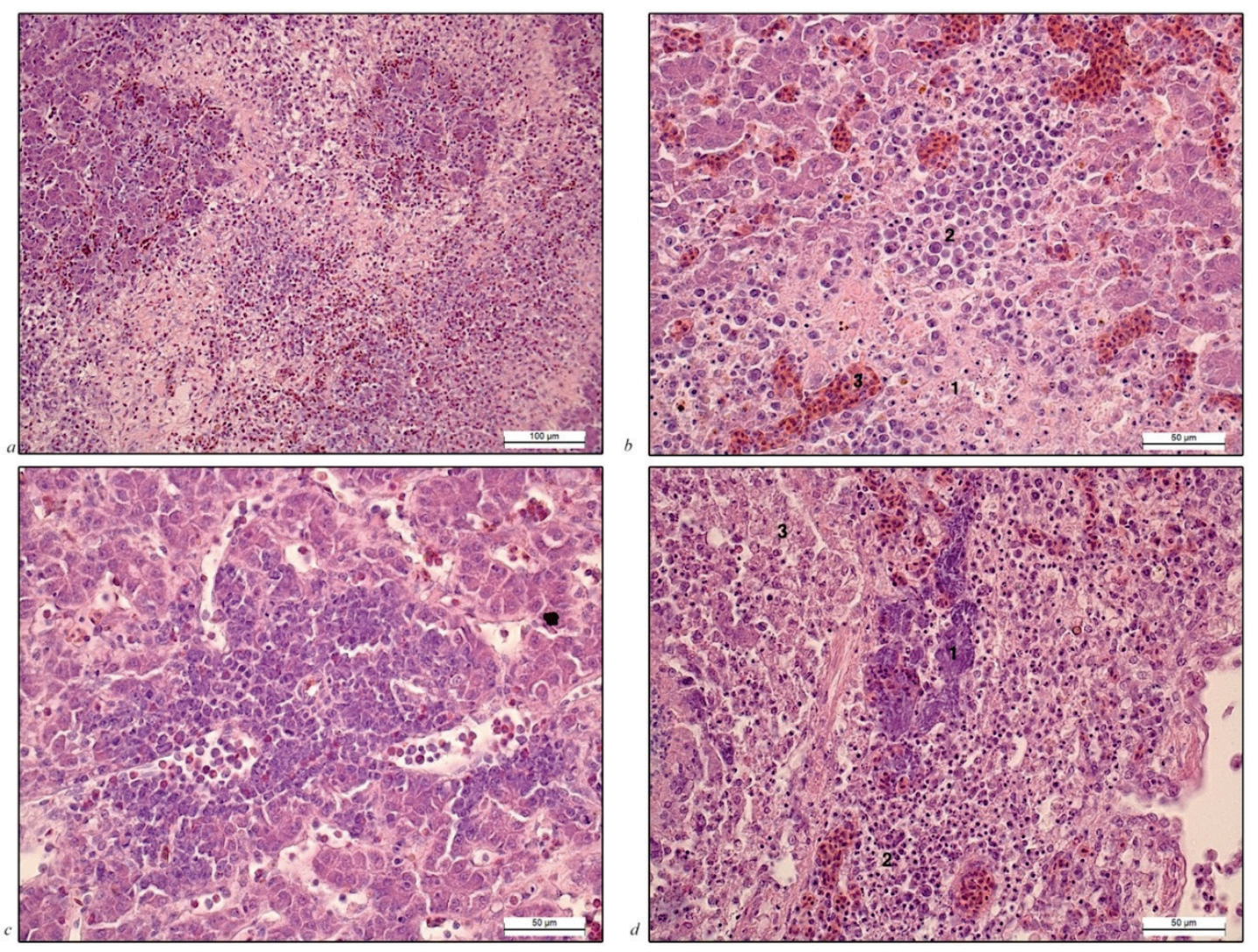

Fig. 3. Pathohistological changes in the liver of chickens infected with Salmonella pullorum: $a$-multifocal coagulation necrosis of hepatocytes with the further fibrosis; $b$ - the liver of chickens aged 10 days: 1 - hepatocyte necrosis; 2 - heterophilic infiltration; 3 - dilation of intraparticle capillaries; $c$-perivascular infiltration by heterophiles, plasma cells, and lymphocytes; $d$-the liver of chickens aged 14 days: 1 -colonies of microorganisms; 2 - heterophilic infiltration, plasma cells accumulation, lymphocytes; 3 - necrosis of hepatocytes; hematoxylin and eosin
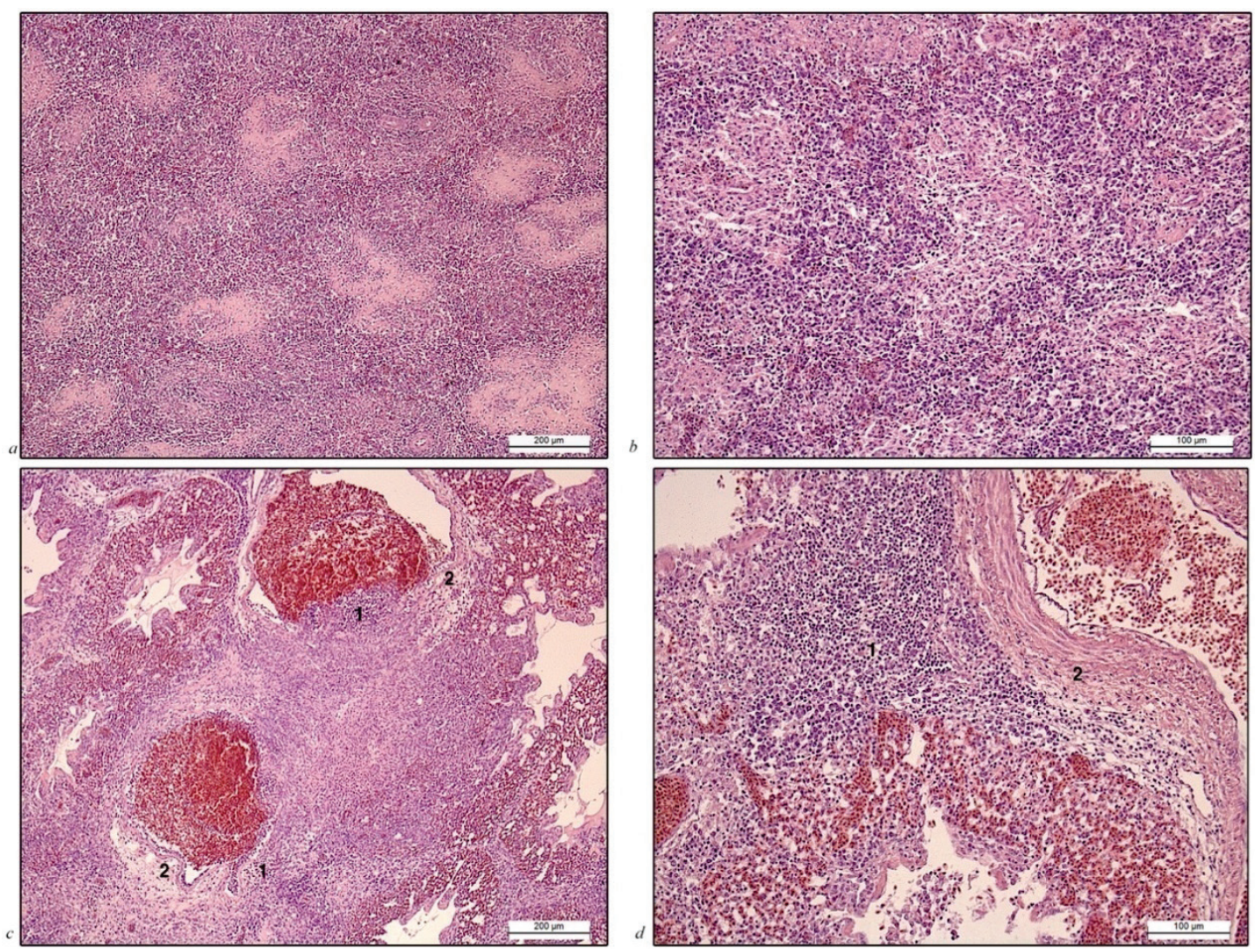

Fig. 4. Pathohistological changes in the spleen and lungs of chickens infected with Salmonella pullorum: $a$ - the spleen: diffuse coagulation necrosis of lymph nodes; $b$ - the spleen: delymphatization of lymphoid nodules with the development of coagulation necrosis; $c$ - the lungs: acute congestive hyperemia; 1 - massive infiltration of bronchial pairs by heterophiles, plasma cells, and lymphocytes; 2 - perivascular edema; $d$-the lungs: 1 -acute congestive hyperemia of the parabronchi, lymphoid infiltration; 2 - perivascular edema; hematoxylin and eosin 

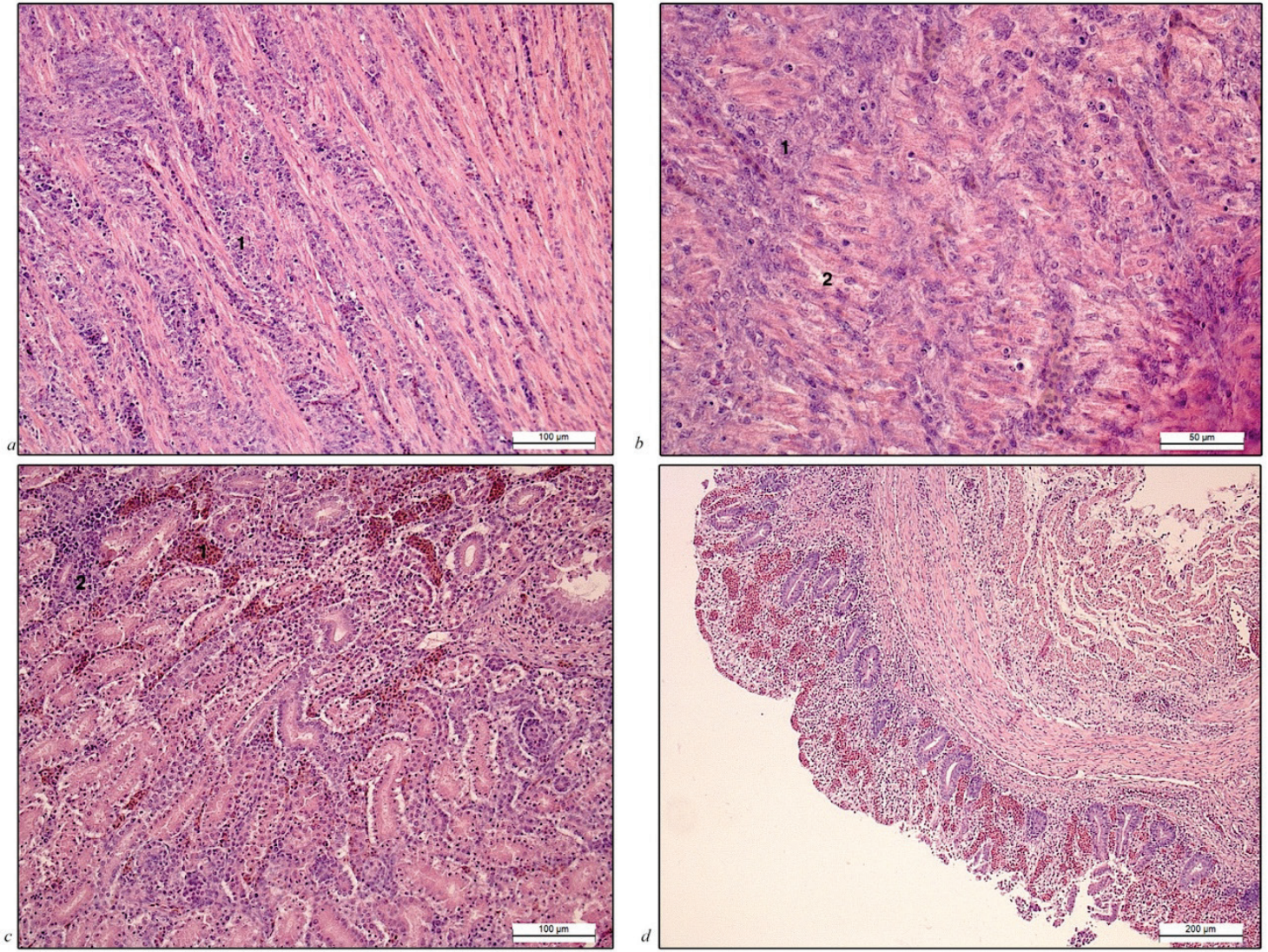

Fig. 5. Pathohistological changes in the organs of chickens infected with Salmonella pullorum:

$a, b$-the heart of chickens aged 10 days: 1 -heterophilic infiltration of cardiomyocytes; 2 -cardionecrosis; $c$-the kidney of chickens aged 14 days:

1 - duct epithelial dystrophy, stasis; 2 - cellular infiltration; $d$ - the rectum: acute catarrhal hemorrhagic desquamative colitis; hematoxylin and eosin

Table 1

Pathological and histopathological changes detected in chickens in case of spontaneous lesions by microorganisms S. pullorum

\begin{tabular}{|c|c|c|c|c|c|}
\hline $\begin{array}{l}\text { Typical pathohistological changes } \\
\text { in the chickens' organs }\end{array}$ & $\begin{array}{c}\text { Farm } 1 \text {. The number of } \\
\text { dead chickens, } 10 \text { to } 20 \\
\text { days }(n=1750)\end{array}$ & $\begin{array}{c}\text { Farm } 2 \text {. The number of } \\
\text { dead chickens, } 10 \text { to } 20 \\
\text { days }(n=2560)\end{array}$ & $\begin{array}{c}\text { Farm } 3 \text {. The number of } \\
\text { dead chickens, } 10 \text { to } 20 \\
\text { days }(n=2150)\end{array}$ & $\begin{array}{c}\text { Farm } 4 \text {. The number of } \\
\text { dead chickens, } 10 \text { to } 20 \\
\text { days }(n=3068)\end{array}$ & $\begin{array}{l}\% \text { of the } \\
\text { dead } \\
\text { chickens }\end{array}$ \\
\hline Fatty liver degeneration with miliary necrosis & - & 640 & 538 & 767 & 25 \\
\hline $\begin{array}{l}\text { Hepatomegaly with hemorrhage under the capsule and } \\
\text { heart necrosis }\end{array}$ & 1137 & 1664 & 1397 & 1995 & 65 \\
\hline Catarrhal hemorrhagic enteritis & 227 & - & - & 399 & 13 \\
\hline Pneumonia & 297 & - & - & - & 17 \\
\hline Acute venous hyperemia of the lungs with necrotic foci & - & 921 & 774 & 1104 & 36 \\
\hline Splenomegaly & - & 51 & - & - & 2 \\
\hline Spot hemorrhages in the spleen parenchyma & 455 & - & 559 & 797 & 26 \\
\hline Renal dystrophy & 630 & - & - & 1104 & 36 \\
\hline Liver multifocal necrosis & 1487 & 2176 & 1827 & 2607 & 85 \\
\hline Perivascular cell infiltration & 1260 & 1843 & 1548 & 2208 & 72 \\
\hline Heterophilic infiltration of the small intestinal mucosa & - & - & - & 460 & 15 \\
\hline Necrosis of the spleen lymphoid nodules & 1137 & 1664 & 1368 & 1994 & 65 \\
\hline
\end{tabular}

The pathohistological study performed by Hossain (Hossain et al., 2006) indicated the development of fatty degeneration of the hepatocytes, congestion phenomena combined with hemorrhage, isolated necrotic nodules with infiltration of leukocytes, mainly mononuclear cells and heterophiles. Wigley et al. (2001), Garcia et al. (2010), Kaoud et al. (2018) reported nodular heart disease and significant mononuclear cell infiltration leading to atrophy, necrosis, and replacement of muscle tissue with connective tissue elements.

\section{Conclusion}

A pathomorphological study revealed the characteristic changes that occurred during the infectious process. They included bacteremia with subsequent parenchymal diffusion of microorganisms into the internal organs and the progression of changes inherent in the granulomatous inflammatory reaction. Thus, the combination of typical signs in the localization of pathological processes was noted from the morphological point

of view. They include focal myocarditis, multifocal hepatocyte coagulative necrosis, fatty degeneration of hepatocytes, intraparenchymal multifocal proliferates in the lungs, hemorrhagic desquamative colitis, and dystrophic changes of the nephrothelium of the renal tubules.

\section{References}

Amy, M., Velge, P., Senocq, D., Bottreau, E., Mompart, F., \& Virlogeux-Payant, I. (2004). Identification of a new Salmonella enterica serovar enteritidis locus involved in cell invasion and in the colonisation of chicks. Research in Microbiology, 155(7), 543-552

Arora, D., Kumar, S., Jindal, N., Narang, G., Kapoor, P. K., \& Mahajan, N. K. (2015). Prevalence and epidemiology of Salmonella enterica serovar gallinarum from poultry in some parts of Haryana, India, Veterinary World, $8(11)$ $1300-1304$.

Basnet, H. B., Kwon, H. J., Cho, S. H., Kim, S. J., Yoo, H. S., Park, Y. H., Yoon, S. I., Shin, N. S., \& Youn, H. J. (2008). Reproduction of fowl typhoid by respiratory challenge with Salmonella gallinarum. Avian Diseases, 52(1), 156-159. 
Basu, S., Dewan, M. L., \& Suri, J. C. (1975). Prevalence of Salmonella serotypes in India: A 61-year study. Bulletin of the World Health Organization, 52(3), 331-336.

Belih, S., El-Hadad, S., Amen, G., \& Basiony, M. (2016). Influence of sodium butyrate on Salmonella infection in broiler chicks. Benha Veterinary Medical Journal, 31(2), 21-32.

Calnek, B. W., Barnes, H. J., Beard, C. W., McDougald, L. R., \& Saif, U. M. (1997). Diseases of poultry. 10th edn., Iowa State University Press, Ames.

Chishti, M. A., Khan, M. Z., \& Irfan, M. (1985). Pathology of liver and spleen in avian salmonellosis. Pakistan Veterinary Journal, 5, 157-160.

Christensen, J. P., Olsen, J. E., Hansen, H. C., \& Bisgaard, M. (1992). Characterization of Salmonella enterica serovar gallinarum biovars gallinarum and pullorum by plasmid profiling and biochemical analysis. Avian Pathology, 21(3), $461-470$.

Garcia, K. O., Santana, A. M., Freitas Neto, O. C., Simplício, K. M. M. G., Alessi, A. C., Júnior, A. B., \& Fagliari, J. J. (2010). Experimental infection of commercial layers using a Salmonella enterica sorovar gallinarum strain: Blood serum components and histopathological changes. Brazilian Journal Veterinary Pathology, 3(2), 111-117.

Hafeji, Y. A., Shah, D. H., Joshi, B. P., Roy, A., \& Prajapati, K. S. (2001). Experimental pathology of field isolates of Salmonella gallinarum in chickens. Indian Journal of Poultry Science, 36, 338-340.

Hossain, M. S., Chowhury, E. H., Islam, M. M., Haider, M. G., \& Hossain, M. M. (2006). Avian Salmonella infection isolation and identification of organisms and histopathological study. Banglidesh Journal of Veterinary Medicine, 4, 7-12.

Kaoud, H. A., El-Babbly, M. A., El-Iraqi, K. G., \& Khalil, M. M. (2018). Prevalence of Salmonella spp. in some broiler farms in different Egyptian governorates. Journal of Veterinary Medical Research, 25, 164-173.

Kashani, B., Kamil, S. A., Beigh, A. B., Shah, S. A., Wani, B. M., Kawoosa, M. S., Maqbool, M., \& Yadav, P. K. (2021). Isolation, identification and molecular characterization of Salmonella enterica subsp. enterica serovar gallinarum from poultry farms of Central Kashmir, North India. Indian Journal Veterinary Pathology, 45(1), 1-6.

Khan, M., Bari, A. S. M., Islam, M. R., Das, P. M., \& Ali, M. Y. (1998). Pullorum disease in semi-mature chicks and its experimental pathology. Bangladesh Journal of Veterinary Medicine, 32, 124-128.
Merkulov, G. A. (1969). Kurs patologicheckoj tekhniki [Course of pathohistological techniques]. Medicine, Moscow (in Russsian).

Nazir, S., Kamil, S., Darzi, M. M., Mir, M., \& Amare, A. (2012). Pathology of spontaneously occurring salmonellosis in commercial broiler chickens of Kashmir Valley. Journal of World's Poultry Research, 2(4), 63-69.

Paul, P. K., Haider, M. G., Khaton, R., Ghosh, S. K., Das, P. M., \& Hossain, M. M. (2015). Pathological investigation of fowl typhoid in chickens in Mymensingh. Annals of Bangladesh Agriculture, 19, 33-41.

Prasanna, K., \& Paliwal, O. P. (2003). Experimental fowl typhoid and pullorum disease in chickens, clinical and pathomorphological studies. Indian Journal Veterinary Pathology, 26, 27-29.

Rosu, V., Chadfield, M. S., Santona, A., Christensen, J. P., Thomsen, L. E., Rubino, S., \& Olsen, J. E. (2007). Effects of crp deletion in Salmonella enterica serotype gallinarum. Acta Veterinaria Scandinavica, 49, 14

Saha, A. K., Sufian, M. A., Hossain, M. I., \& Hossain, M. M. (2012). Salmonellosis in layer chickens: Pathological features and isolation of bacteria from ovaries and inner content of laid eggs. Journal of the Bangladesh Agricultural University, 10(1), 61-67.

Shivaprasad, H. L. (2000). Fowl typhoid and pullorum disease. Revue Scienfique et Technique, 19(2), 405-424.

Snoeyenbos, G. H. (1991). Pullorum disease. In: Calnek, B. W., Barnes, H. J., Beard, C. W., Reid, W. M., \& Yoder, H. W. (Eds.). Diseases of poultry. Iowa State University Press, Ames. Pp. 73-86.

Wang, X., Wang, H., Li, T., Liu, F., Cheng, Y., Guo, X., Wen, G., Luo, Q., Shao, H., Pan, Z., \& Zhang, T. (2020). Characterization of Salmonella spp. isolated from chickens in Central China. BMC Veterinary Research, 16(1), 299.

Wigley, P., Berchieri, A. J., Page, K. L., Smith, A. L., \& Barrow, P. A. (2001). Salmonella enterica serovar pullorum persists in splenic macrophages and in the reproductive tract during persistent, disease-free carriage in chickens. Infection and immunity, 69(12), 7873-7879.

Wigley, P., Jones, M. A., \& Barrow, P. A. (2002). Salmonella enterica serovar pullorum requires the Salmonella pathogenicity island 2 type III secretion system for virulence and carriage in the chicken. Avian Pathology, 31(5), 501-506. 